\title{
ESTUDIO HISTÓRICO-EPISTEMOLÓGICO SOBRE LA TEORÍA O MODELO DE LA ESTRUCTURA QUÍMICA DEL ACIDO DESOXIRRIBONUCLEICO (ADN)
}

\author{
Angélica María García Torres
}

\section{RESUMEN}

En este artículo se presenta un estudio del proceso histórico-epistemológico desde la perspectiva lakatosiana de la investigación científica llevada a cabo por J. Watson y $F$, Crick, que los condujo a proponer el modelo de doble hélice para la estructura del ADN, en el año de 1953.

PALABRAS CLAVES: epistemología lakatosiana, heurística negativa, heurística positiva, hipótesis auxiliar, historia interna..

\section{SUMARY}

In this paper shows historical-epistemological process from lakatosian view of the scientific research to take to J.Watson \& F.Crick,to elucidate the pattern of double helix of DNA structure in 1953.

KEY WORDS: Lakatosian epistemology, negative heuristic, positive heuristic, auxiliary hypothesis, internal history.

\section{INTRODUCCIÓN}

El proceso que condujo a la propuesta de la estructura del ácido desoxirribonucleico (ADN) puede ser analizado desde la perspectiva de la metodología de un programa de investigación (Lakatos, 1983), para demostrar que no obedeció a observaciones ateóricas sino que requirió metodologías, transformaciones novedosas y persistencias conceptuales.

Desde lo epistemológico, la propuesta lakatosiana de programas de investigación básicamente se centra en la existencia de una heurística que permite la solución de problemas, la asimilación de anomalías, así como la predicción de hechos nuevos. Este tipo de heurística le facilita al investigador, tanto los caminos que debe evitar (heurística negativa), como los caminos que debe seguir (heurística positiva). Un programa de investigación no progresa mediante el desarrollo de teorías aisladas, pruebas de ensayo y error o métodos basados únicamente en la experimentación ateórica.

La estructura química del ADN pertenece a un programa de investigación que tuvo confrontaciones teóricas con programas rivales, las cuales se desarrollaron simultáneamente en diferentes países. La mayor novedad fáctica y estructura lógica del modelo presentado por el biólogo J.Watson y el físico F.Crick (Watson, 1967), es que

\footnotetext{
- Química. Docente Universidad Pedagógica y Tecnológica de Colombia-UPTC (Tunja). Estudiante de Maestría en Docencia de la Química, Grupo de Investigación: Representaciones y Conceptos Científicos. Universidad pedagógica Nacional.

angelica_garcia01@pedagogica.edu.co, angelgarto@hotmail.com
} 
prevaleció frente a los modelos propuestos, entre otros, por los científicos L. Pauling (Pauling \& Corey, 1953) y S. Furberg (Furberg, 1952).

En el presente trabajo, además del artículo original (Watson \& Crick, 1953), se acude a la narración de todo el proceso, presentado por J.Watson (1967), en el libro que al respecto de éste escribiere.

\section{ANTECEDENTES (Watson, 1967)}

La formulación del modelo estructural químico del ADN se debió principal, aunque no únicamente, al trabajo de cinco investigadores: Maurice Wilkins, Rosalind Franklin, Linus Pauling, Francis Crick y James Watson. La vinculación de J.Watson con F.Crick se sucedió cuando en el otoño de 1951, el primero llegó al Laboratorio Cavendish de la Universidad de Cambridge, para unirse con un pequeño grupo de físicos y químicos que trabajaban sobre las estructuras tridimensionales de las proteínas.

Al frente del grupo se hallaba el químico austriaco Max Perutz, quien llevaba más de diez años recopilando datos sobre la difracción de los rayos $X$ en los cristales de hemoglobina; le ayudaba en ello el físico Sir Lawrence Bragg, director del Cavendish. Durante casi cuarenta años; Sir L. Bragg, premio Nóbel y uno de los fundadores de la cristalografía, había estado utilizando los métodos cristalográficos para resolver estructuras relacionadas con el estudio de las proteínas, las más complicadas de todas las moléculas por aquel tiempo.

J.Watson, gracias a una beca de postdoctorado, había llegado a Europa con el fin de investigar en torno a la composición química del $A D N$; interés surgido del deseo de comprender qué eran los genes. Fue en la primavera de 1951, al participar en una reunión científica en Nápoles relacionada con el estudio de la estructura de las macromoléculas biológicas, que conoció los trabajos cristalográficos del ADN expuestos por el físico M. Wilkins. A partir de esto, J. Watson, tomó especial atención sobre la teoría de difracción de los rayos $\mathrm{X}$, razón por la cual solicitó su admisión al laboratorio de Cambridge, especialista en estos estudios; donde fue aceptado luego de difíciles y fatigosas gestiones, precisamente por su poca comprensión sobre dicha teoría. Es de anotar, que simultáneamente, F.Crick se encontraba dedicado ya al estudio del ADN en el laboratorio de Cambridge.

El desarrollo de la teoría molecular del ADN inicialmente, tiene como sustento teórico los estudios relacionados con las estructuras tridimensionales de las proteínas, ya que se creía que tales biomoléculas eran las determinantes de la transmisión de la herencia biológica. A pesar de ello, un factor importante que contribuyó en F. Crick para que abandonara la física y desarrollara un intenso interés por la biología fue la lectura del libro “¿Qué es la Vida ?" (Schrodinger, 1946). Este libro sugería que los genes eran los componentes clave de las células vivas, luego para la comprensión de la vida era necesario conocer el modo de actuar de los genes. Paralelamente, el bacteriólogo Oswald T. Avery realizaba en el Rockefeller Institute de Nueva York varios experimentos que demostraban que los caracteres hereditarios podían ser transmitidos de una célula bacteriana a otra por moléculas purificadas de ADN. Y puesto que se sabía que el ADN está presente en los cromosomas de todas las células, los experimentos de O.T. Avery sugerían que todos los genes estaban compuestos de ADN. 
Durante la década comprendida entre 1940-1950, predominaba entre la comunidad de genetistas, la idea de que los virus eran genes desnudos, por lo que, el mejor modo de averiguar qué era y como funcionaba un gen consistía en estudiar las propiedades de los virus, comenzando por los virus más simples: los fagos. Al frente de este grupo se hallaban el microbiólogo italiano Salvador Luria (supervisor de Watson) y Max Delbruck, físico teórico de origen alemán. Mientras M. Delbruck confiaba en que los experimentos puramente genéticos podrían resolver el problema, S. Luria sostenía que la solución llegaría sólo después de haber sido develada la estructura química de los virus.

El sólo examen de las placas cristalográficas del ADN impediría un gran número de puntos de partida erróneos. Por fortuna, existía ya una fotografía bastante buena tomada cinco años atrás, W. T Astbury (1947), las que junto con las fotografías tomadas por M. Wilkins, fueron significativas. Cabe destacar, que para J. Watson y F. Crick no hubo dificultad en contar con el apoyo de M. Wilkins pues éste también pensaba en una estructura de hélice para el ADN. Sin embargo, erróneamente, consideraba que para construir la hélice eran necesarias tres cadenas polinucleótidas.

Las estructuras helicoidales constituían el centro de interés en el laboratorio de Cambridge, a causa de la estructura de hélice alfa para las proteínas propuesta por el químico L. Pauling, la cual debería ser comprobada, con base en una teoría y en una deducción matemática general, que posteriormente postuló F.Crick junto con su colega, el físico, Bill Cochran; dicha teoría, constituyó el primer logro científico significativo de $\mathrm{F}$. Crick; además, constituyó parte del núcleo firme del programa de investigación que empezaba a desarrollar junto con J.Watson.

\section{HISTORIA INTERNA DE LA ELUCIDACIÓN DEL MODELO DEL ADN (Watson, 1967).}

J.Watson y F.Crick partieron del supuesto de que la molécula de ADN contenía un gran número de nucleótidos enlazados linealmente en una forma regular. Aunque los químicos orgánicos del laboratorio próximo de Alexander Todd, consideraban ésta como la disposición básica, se hallaban aún muy lejos de demostrar químicamente que todos los enlaces internucleótidos eran idénticos. A partir de los estudios cristalográficos de los físicos, M. Wilkins y R. Franklin; y de que además, tanto J.Watson como F.Crick no comprendían la formación de agregados cristalinos de las moléculas de ADN, se vieron en la necesidad de considerar la cadena azúcar-fosfato como extremadamente regular para así buscar una configuración tridimensional helicoidal en la que todos los grupos medulares tuvieran un idéntico entorno químico. Bajo esta primera hipótesis auxiliar comenzó el desarrollo de una posible heurística positiva en su programa de investigación.

Esto les llevó a suponer que la solución del problema de la estructura del ADN podría ser más complicada que el de la hélice alfa de las proteínas, ya postulada por L. Pauling. Sin embargo, M. Wilkins dijo a F.Crick que el diámetro de la molécula de ADN era más grueso de lo que sería, si sólo estuviera presente una única cadena polinucleótida. Por esto, $F$. Crick tomó como subsecuente hipótesis el suponer que la molécula de ADN era una hélice compuesta, formada de varias cadenas polinucleótidas arrolladas una en torno a la otra. De ser así, antes de comenzar la construcción de modelos moleculares (“...en vez de lápiz y papel, los principales instrumentos de trabajo eran modelos moleculares que se asemejaban a los juguetes de niños en edad preescolar...") (Watson, 1967), era preciso decidir si las cadenas estarían unidas por enlaces de hidrógeno o por enlaces iónicos, que afectarían a los grupos fosfatos, de carga negativa. 
Una complicación presente durante el desarrollo del programa de investigación fue el hecho de la existencia de cuatro tipos de nucleótidos en el ADN, entonces, no podía ser una molécula regular. No obstante, los cuatro nucleótidos no eran completamente diferentes, pues cada uno contenía los mismos componentes de azúcar y fosfato. Su singularidad radicaba en sus bases nitrogenadas, que eran o una purina (adenina 0 guanina) o una pirimidina (citosina o timina).

Puesto que los enlaces entre los nucleótidos afectaban sólo a los grupos fosfato y azúcar, no era tan aventurada la posición o hipótesis de J.Watson y F.Crick de que el mismo tipo de enlace químico unía a todos los nucleótidos. Así pues, al construir modelos moleculares, postularían que la cadena azúcar-fosfato era regular y se situaba en el centro de la hélice; mientras que el orden de bases era irregular y se situaba en el exterior de la hélice.

Entonces, los últimos avances les permitieron aplicar, de acuerdo a la teoría CochranCrick sobre estructuras helicoidales, sólo un pequeño número de soluciones formales compatibles con los datos experimentales de R. Franklin. Así, la clave estaba en decidir cuál era el número de cadenas polinucleótidas que existían dentro de la molécula de ADN. Sin embargo, los datos cristalográficos eran compatibles con dos, tres o cuatro cadenas, por lo que todo era cuestión de los ángulos y los radios con que las cadenas de ADN se ubicaban en torno a un eje central.

Decidieron iniciar la solución referente a la explicación de la estructura química del ADN partiendo de un primer modelo en el que la cadena azúcar-fosfato se hallaba en el centro de la molécula (Figura 1), con lo cual se obtiene una estructura lo suficientemente regular, como para dar los módulos de difracción cristalina, observados por M. Wilkins y R. Franklin. J.Watson y F.Crick estaban conscientes, en aquel momento, de que debían ocuparse de la secuencia irregular de las bases situadas en la parte externa; dificultad o anomalía presente dentro de su programa de investigación, la cual suponían se resolvería cuando la disposición interna fuera localizada de un modo correcto.

El problema central era el de la neutralización de las cargas negativas de los grupos fosfato de la molécula de $A D N$, dado que no sabían cómo se situaban en tres dimensiones los iones inorgánicos. El desarrollo de un programa de investigación requiere de un trabajo en comunidad, no tiene lugar si en él se utilizan teorías aisladas o métodos experimentales ateóricos. Por ello, J. Watson y F.Crick acudieron al estudio de las publicaciones de $\mathrm{L}$. Pauling relacionadas con la química estructural de los iones inorgánicos, ya que la clave del problema radicaba en deducir una disposición adecuada de tales iones; lo cual lograron, como una solución parcial al problema. 


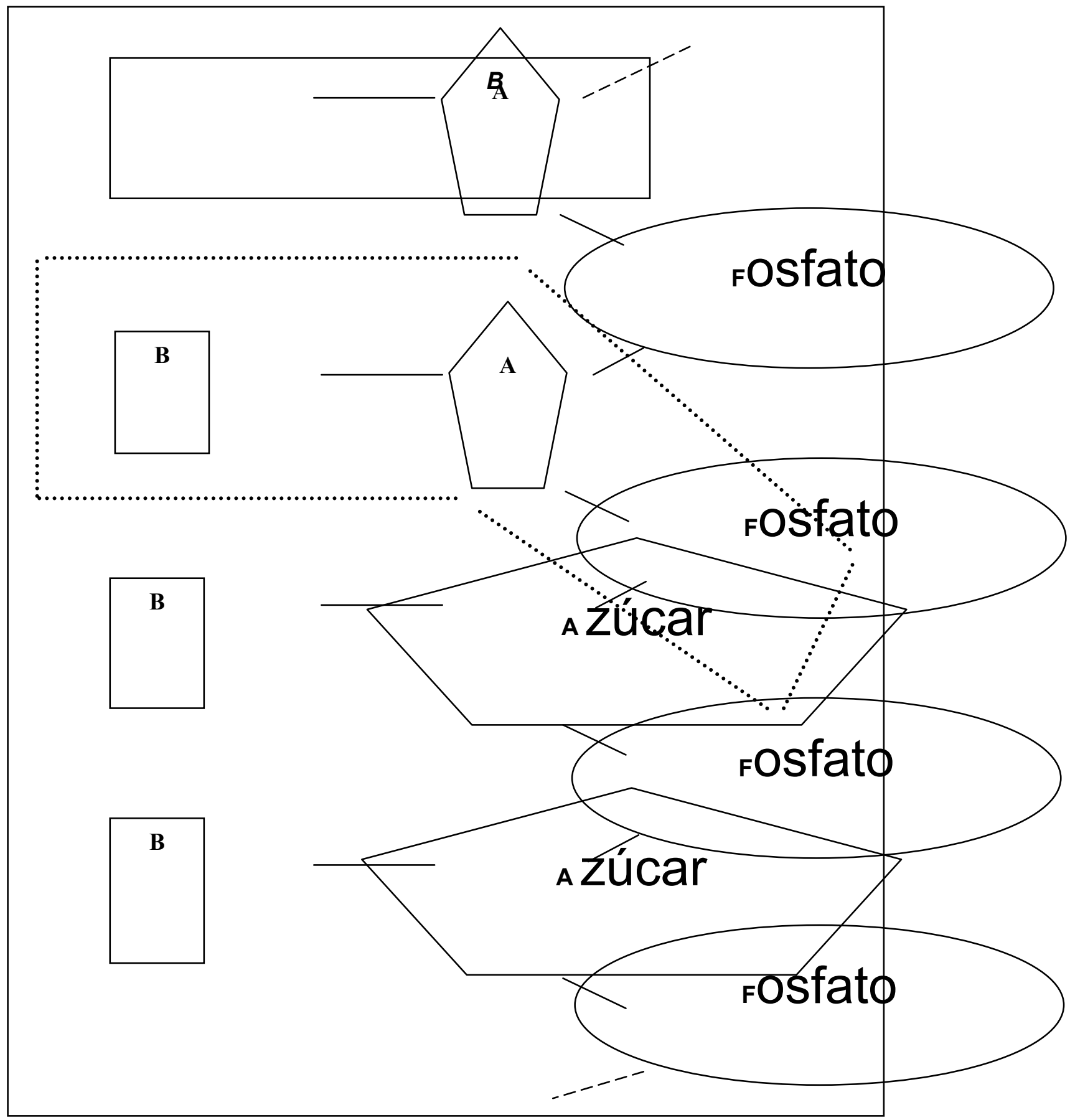

Figura 1. Primer fragmento de ADN imaginado por el programa de investigación. B: base nitrogenada, A: azúcar, F: fosfato. (Watson, 1967)

Al mismo tiempo, mientras F.Crick se concentraba en el significado de los diagramas de rayos $X$, J.Watson se dedicó a reconstruir los diversos modelos moleculares en varias cadenas, disponiéndolos en línea de nucleótidos, ya que consideraba que aunque las cadenas de ADN son muy largas en la naturaleza, no había razón para formar un modelo molecular demasiado extenso, en la seguridad de que se trataba de una hélice, cuya distribución de posiciones para un solo par de nucleótidos generaba automáticamente la disposición de todos los demás componentes. Esta seguridad, de un modelo estructural helicoidal del ADN, puede considerarse, desde el punto de vista lakatosiano, como parte del núcleo firme del programa de investigación formulado por estos científicos. 
Luego de varios análisis, J.Watson y F.Crick habían desechado las hélices monocatenarias por su incompatibilidad con las pruebas de que disponían; dentro del desarrollo del programa de investigación consideraron que, en cuanto a las fuerzas que mantenían unidas las cadenas, lo mejor era suponer que eran puentes salinos, en los que cationes divalentes, como por ejemplo, el $\mathrm{Mg}^{++}$(Figura 2) unían a dos o más grupos fosfato (Watson, 1967).

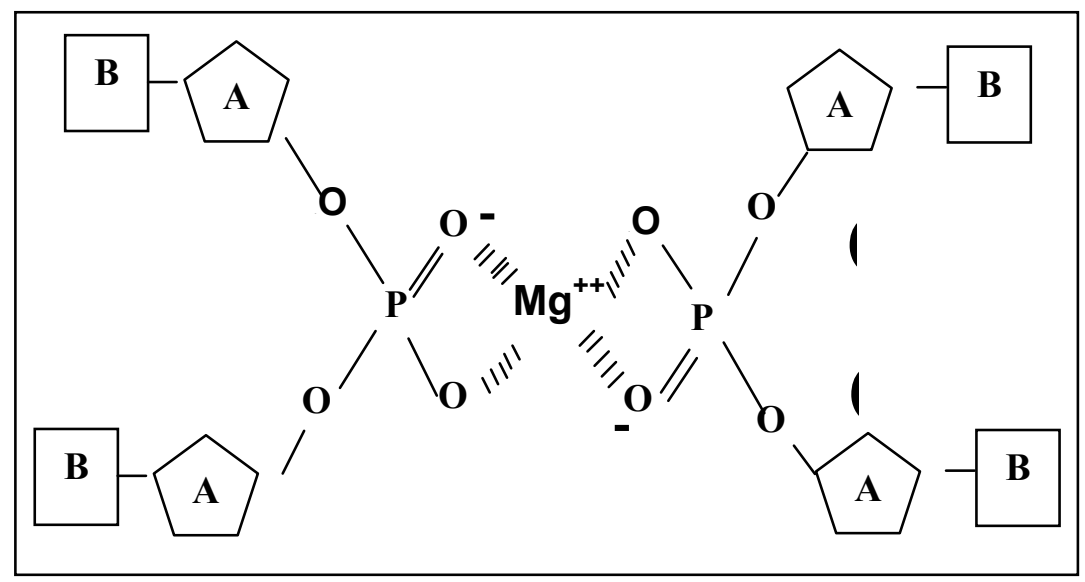

Figura 2. Hipótesis de cómo los iones $\mathrm{Mg}^{++}$grupos de fosfato de carga negativa en el centro de la hélice compuesta (Watson, 1967).

Watson y Crick pensaron que los enlaces de fosfodiéster que unían los sucesivos nucleótidos del ADN, podían existir en una gran variedad de formas, por lo que propusieron tres cadenas que se arrollaban entre sí, dando lugar a una repetición cristalográfica, cada $28 \AA$, a lo largo del eje de la espiral. De este modo, dicha característica se ajustaba a lo exigido por las fotografías de M. Wilkins y R. Franklin. Sin embargo; al cotejar su modelo con las mediciones cuantitativas de R. Franklin, encontraron como anomalía al desarrollo de tal hipótesis, que dicho modelo no concordaba con los contenidos de agua obtenidos experimentalmente.

Esta conclusión aumentó, de un modo alarmante, el número de potenciales modelos moleculares para el ADN. La incertidumbre de verificar si ésta estructura dependía de los iones utilizados para neutralizar los grupos fosfato negativos (iones que suponían correspondían a $\mathrm{Mg}^{++}$, podía llevarlos a una regresión del programa de investigación, ya que eran falsas las hipótesis anteriormente planteadas.

J.Watson y F.Crick retomaron sus estudios dejando de lado la construcción de modelos moleculares basados en ejes de azúcar-fosfato. Cualquier modelo que situara la cadena azúcar-fosfato en el centro de una hélice, obligaba a los átomos a estar más próximos de lo que permitían las "...leyes de la química..." establecidas (Watson, 1967). El problema requería de un nuevo enfoque, un cambio en el desarrollo de las hipótesis auxiliares que hasta ahora habían dominado el curso del programa de investigación.

Fue durante el Congreso de la Royal Society, realizado en el año de 1952, que J. Watson tuvo la oportunidad de conocer al microbiólogo francés André Lwoff, quien se ocupaba del papel que tenían los metales divalentes en la multiplicación de los fagos, y quien estaba interesado en la hipótesis de Watson, de que los iones tenían una importancia decisiva en la estructura del ácido nucleico. Es de destacar que el interés de buscar relación entre los postulados de A. Lwoff y J. Watson radicaba en los estudios 
cristalográficos sobre el virus del mosaico del tabaco (VMT), realizados de forma simultánea por J. Watson, los cuales verificaban la estructura helicoidal de éstos virus. Sin embargo, el VMT contenía una estructura de ARN y no de ADN.

Entusiasmados por sus supuestos adelantos relacionados con la estructura helicoidal, así como por la importancia de los iones metálicos en ella; J.Watson y F.Crick toman, como hipótesis dentro de su programa de investigación, los trabajos acerca de las proporciones relativas de las bases nitrogenadas (purinas y pirimidinas) en la estructura del ADN, realizados por el bioquímico austriaco Erwin Chargaff (Chargaff, 1952); en donde, para todos los preparados de $A D N$, el número de moléculas de adenina $(A)$ era muy similar al número de moléculas de timina $(T)$, mientras que el número de moléculas de guanina $(G)$ era muy semejante al número de moléculas de citosina $(\mathrm{C})$. Además, la proporción entre el conjunto de bases adenina-timina y el de guanina-citosina variaba según su origen biológico. En el ADN de algunos organismos predominaban $A$ y $T$, mientras que en otras prevalecían $\mathrm{G}$ y $\mathrm{C}$. Chargaff no ofrecía ninguna explicación de sus resultados, aunque pensaba que eran significativos.

Así fue como F.Crick pensó en la posibilidad de verificar la existencia de "un principio biológico perfecto", asociando los aportes del químico teórico John Griffith, interesado en los esquemas de repetición de los genes. Por aquel tiempo, algunos genetistas sostenían que la duplicación del gen requería la formación de una imagen complementaria, en la que la forma estaba relacionada con la superficie original como una cerradura respecto a una llave. La imagen complementaria funcionaría entonces como el molde para la síntesis de una nueva imagen.

Tanto para F. Crick como para J. Griffith, era importante detectar las fuerzas de atracción presentes en los nucleótidos, específicamente en sus bases nitrogenadas. F.Crick argumentó que los enlaces de hidrógeno no constituían la solución; por lo que, era necesario postular la existencia de fuerzas específicas de atracción, entre las superficies planas de las bases adenina-timina y guanina-citosina. Relacionando, entonces, lo propuesto por J. Griffith y por E. Chargaff, deduce que los pares señalados se presentan en cantidades iguales. Además, no había razón para excluir la idea de que las regularidades de $\mathrm{E}$. Chargaff tenían su origen en el código genético. Para $\mathrm{F}$. Crick, de alguna manera, grupos específicos de nucleótidos debían codificar aminoácidos específicos y posiblemente la adenina igualaba a la timina a causa de su papel, no sospechado aún, en el ordenamiento de las bases. Hasta aquí cabe recordar que, se tenía como hipótesis auxiliar dentro del programa de investigación que, las bases nitrogenadas se encontraban en la periferia de una posible estructura helicoidal.

Por su parte, J. Watson estudiaba la bioquímica de las interrelaciones del ADN, el ARN y la síntesis de proteínas. Consideró que el ADN era el soporte sobre el que se construirían las cadenas de ARN, a la vez que las cadenas de ARN eran las candidatas más aptas como generadoras de las proteínas. Había algunos datos, extraídos de experimentos realizados con erizos de mar, que hacían pensar en una transformación del ADN en ARN, de ahí la relación ADN---ARN---proteínas, en la que las líneas no significan transformaciones químicas, sino que expresan la transferencia de información genética desde la secuencia de nucleótidos en las moléculas de ADN, a las secuencias de aminoácidos de las proteínas. Este es el fundamento del dogma central de la biología molecular, expuesto por F. Crick en el año de 1958.

Bajo estas condiciones, J. Watson y F. Crick revisan el modelo molecular para el ADN, establecido por L. Pauling. Desde la perspectiva lakatosiana, el programa de investigación 
de L. Pauling, es considerado como programa rival, el cual postulaba una hélice tricatenaria, con los enlaces azúcar-fosfato en el centro. A partir de la revisión hecha al programa de L. Pauling, J. Watson y F. Crick afirmaron que los grupos fosfato del modelo molecular de L. Pauling no estaban ionizados, sino que cada grupo contenía un átomo de hidrógeno enlazado, dando lugar a una biomolécula neutra. De ser así, el ácido nucleico propuesto por L. Pauling no era un ácido. Los hidrógenos formaban parte de los enlaces que unían las tres cadenas. Sin los átomos de hidrógeno, las cadenas se desprenderían unas de otras y la estructura se desmoronaría. Este modelo no era compatible con los fundamentos básicos de la química estructural por lo que aún el desarrollo del programa de investigación de J. Watson y F. Crick podía prevalecer.

Consecutivamente, durante un encuentro entre M. Wilkins y J. Watson, éste último observo los adelantos cristalográficos realizados por R. Franklin, en donde, aún en contra de las suposiciones de R. Franklin se sugería que, cuando las moléculas de ADN estaban rodeadas de una gran cantidad de agua, las formas de cruz que dominaban las fotografías, sólo podían provenir de una estructura helicoidal y que con pocos cálculos se podría determinar el número de cadenas de la molécula. Aunque M. Wilkins admitía que la evidencia en favor de una hélice era ahora abrumadora, el verdadero problema radicaba en la ausencia de cualquier hipótesis estructural que permitiese agrupar regularmente las bases en el interior de la hélice, uno de los planteamientos que si apoyaba R. Franklin.

J. Watson tomó entonces, la iniciativa de construir modelos moleculares de dos cadenas, teniendo como referente que las estructuras biológicas se presentan en parejas. Existían evidencias, tanto teóricas como experimentales, de que el ADN podía ser una hélice que se repetía cada $34 \AA$, a lo largo de su eje; en la que las bases de purina y pirimidina, de un espesor de $3,4 \AA$, se situaban unas encima de otras, en una dirección perpendicular al eje helicoidal, y además que; el diámetro de la hélice era de aproximadamente $20 \AA$.

No obstante, J. Watson se resistía a situar las bases en el interior debido a la sospecha de que dicha posición, implicase un número de modelos posibles, casi infinito. Además, la otra dificultad radicaba en las bases, dado que si se las disponían en el centro, emergía el problema de colocar dos o más cadenas con secuencias irregulares de bases. Estas posibles suposiciones podrían ocasionar, tal vez, una regresión sobre su programa de investigación.

Sin embargo, J.Watson optó por ubicar a las bases nitrogenadas en el centro de la estructura helicoidal bicatenaria. Después de realizar varios modelos en los que bases idénticas, en sus formas enólicas (ya que eran las formas más comúnmente expuestas en los libros de química), se enlazaban entre sí mediante puentes de hidrógeno; concluyó la no factibilidad de dichos modelos moleculares; sumado a esto, se tenía el fundamento teórico y experimental que el químico Jerry Donohue daba sobre la existencia en la naturaleza de las bases nitrogenadas en sus formas cetónicas mas no en las enólicas. Fue así como, teniendo ahora como nueva hipótesis auxiliar las formas ceto de las bases nitrogenadas, que J. Watson se inclinó por acudir a las leyes de Chargaff (1951), en donde el número de radicales de purina igualaba exactamente al número de radicales de pirimidina. J. Watson dedujo que dos secuencias irregulares de bases podían ser introducidas de un modo regular en el centro de una hélice, siempre que la forma cetónica de una purina se enlazara por un puente de hidrógeno con la forma cetónica de una pirimidina. La exigencia de tal enlace de hidrógeno, significaba que la adenina se emparejaría siempre con la timina, mientras que la guanina se emparejaría solamente con la citosina. Lo más significativo era que este tipo de doble hélice sugería un esquema de 
multiplicación en donde se emparejarían siempre A-T y G-C, lo cual significaba, a su vez, que las secuencias de bases de las dos cadenas eran complementarias (Figura 3).

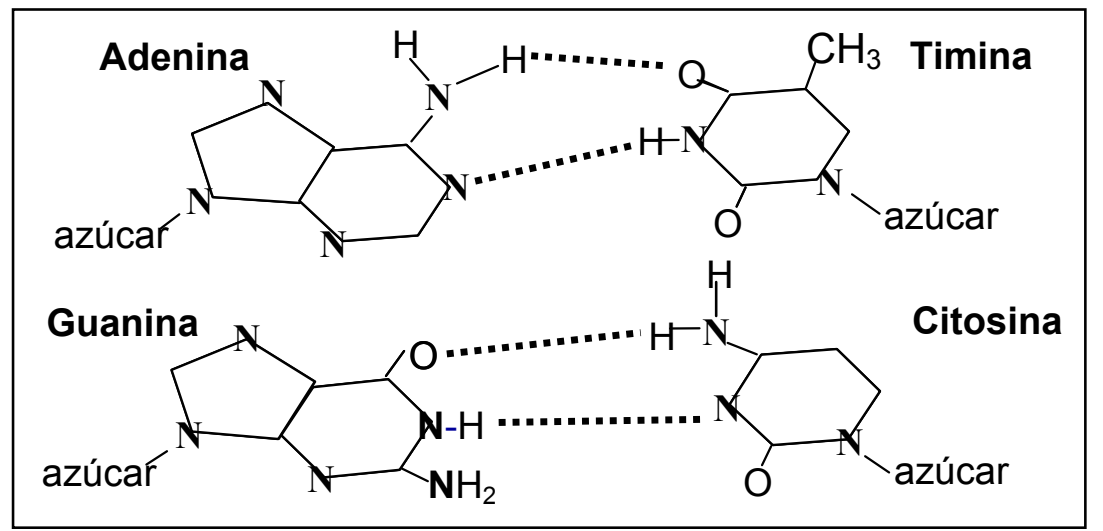

Figura 3. Complementariedad entre bases nitrogenadas (Watson, 1967).

Dada la secuencia de bases de una cadena, quedaba automáticamente determinada la de su compañera. Esto era fácil de imaginar: una cadena aislada podía ser plantilla para la síntesis de una cadena con la secuencia complementaria.

Partiendo de los avances realizados por J.Watson anteriormente aludidos, F. Crick observó el hecho de que los dos enlaces glucosídicos (que unían una base con un azúcar) de cada par de bases estaban sistemáticamente relacionados por un eje perpendicular al eje helicoidal. Así, ambos pares podían ser girados y seguir teniendo sus enlaces glucosídicos apuntados en la misma dirección. Esto tenía la importante consecuencia de que una cadena podía contener, al mismo tiempo, purinas y pirimidinas. Por otra parte, sugería que las dos cadenas debían correr en direcciones opuestas (Figuras 4 y 5). Así se consolidaba cada vez más la explicación una estructura helicoidal bicatenaria, complementaria, que mantenía en su periferia a los grupos azúcar-fosfato de forma regular; mientras que, las bases nitrogenadas, en sus formas cetónicas se encontraban en el centro en relación 1:1 siempre adenina-timina y/o guanina-citosina, unidas entre sí mediante puentes de hidrógeno.

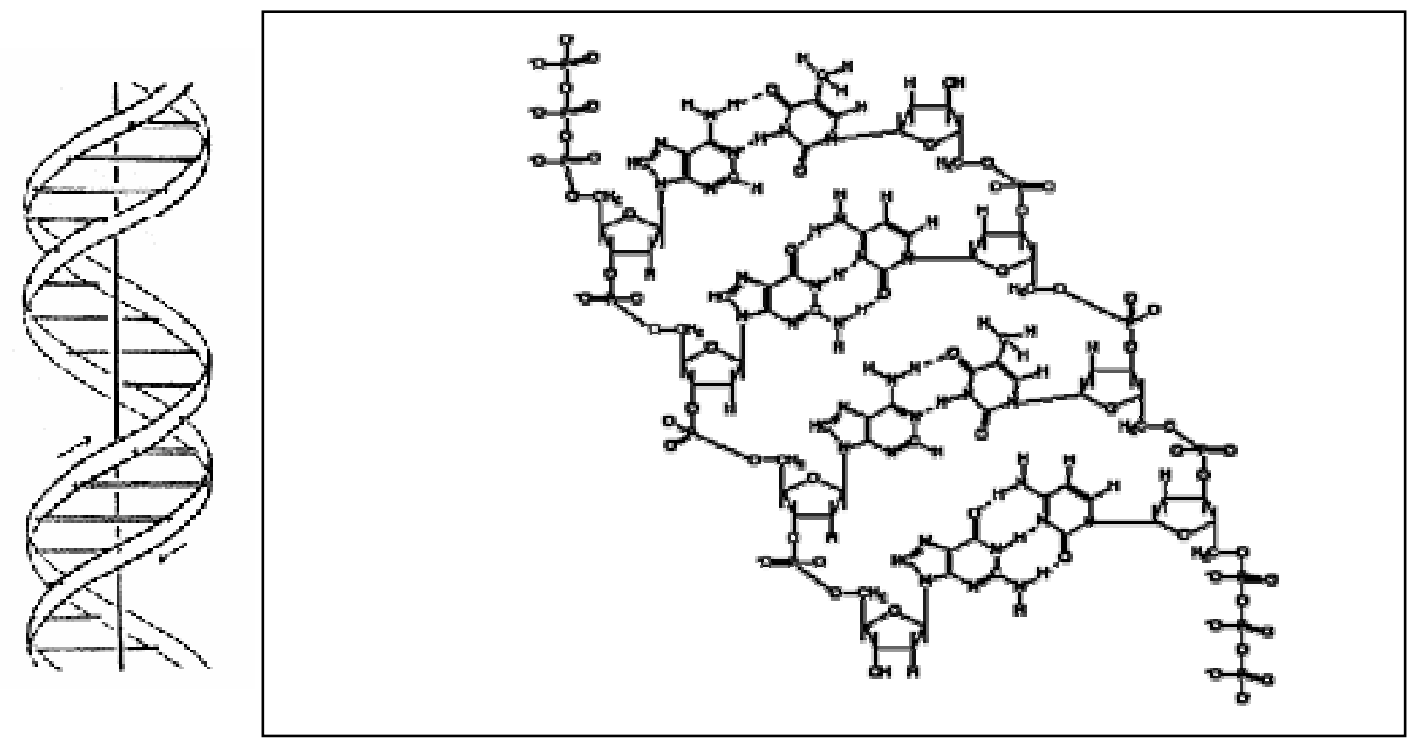

Figuras 4 y 5 . Esquema actual de la doble hélice (Watson, J y Crick, 1953). 
Fue así como después de múltiples intentos, lograron construir un modelo molecular del ADN completo en el que todos los contactos estereoquímicos fueron satisfactorios.

\section{EL MODELO HELICOIDAL DE LA ESTRUCTURA DEL ADN ENMARCADO EN UNA MIRADA LAKATOSIANA.}

Se puede establecer que este progreso de investigación tuvo como núcleo firme las siguientes proposiciones:

- El ADN está presente en los cromosomas de todas las células, está compuesto por desoxirribosa, grupos fosfato y las cuatro bases nitrogenadas. Su estructura química está involucrada en la transmisión de la información genética por cuanto lleva la información hereditaria que determina la estructura de las proteínas.

- La estructura del ADN debe ser helicoidal, y, existe una relación numérica 1:1 entre las bases purínicas y las pirimidínicas.

Como hipótesis auxiliares, algunas de las proposiciones iniciales que se desecharon, así como las técnicas a utilizar para la solución de la estructura del ADN fueron:

- Se refutó que el ADN está compuesto por tres cadenas helicoidales, que el enlace desoxirribosa-fosfato se encuentra en el centro de la estructura tridimensional, mientras que en la parte externa, se ubican las bases nitrogenadas. Además, se refutó la proposición de que las proteínas son las responsables de la herencia genética.

- Fue refutada la suposición de la relevancia de los iones metálicos en la estructura helicoidal del ADN.

- La técnica para comprender la estructura tridimensional del ADN fue el observar su difracción de rayos $X$ así como el utilizar la técnica de modelos moleculares (modelos de rompecabezas), basados en las teorías lógicas y aplicadas de la química estructural.

\section{CAMPO QUE DELIMITÓ EL PROGRAMA DE INVESTIGACIÓN}

Respondió a la pregunta acerca de la composición química de la estructura básica para la transmisión de la información genética; la composición de las moléculas que la componen; la complementariedad entre las cadenas; los análisis cristalográficos sobre la estructura de doble hélice helicoidal; y, la relación y aplicación de las leyes de Chargaff en los contenidos de purinas y pirimidinas presentes. Además, responde a los contenidos de agua (porcentajes) dentro de los ensayos cristalográficos. Así como el carácter ácido del ADN

No explicó la estructura de los genes; ni el dogma central de la biología molecular, es decir, la relación de la transmisión de la información genética desde los cromosomas hasta los aminoácidos (replicación-traducción-transcripción)

Prohibió una posible estructura tridimensional triple helicoidal del ADN; el apareamiento de bases en la región exterior de la estructura de doble hélice; los enlaces azúcar-fosfato en el interior de ella; el apareamiento entre bases idénticas en el interior de la hélice; y la presencia de iones catiónicos en el interior de la estructura sugerida.

No contempló la posibilidad de giro que tienen las cadenas de ADN al sumergirlas en soluciones con concentraciones altas o bajas de sal (ADN Z y ADN B). 


\section{CONCLUSIONES}

Los postulados señalados forman parte del programa de investigación desarrollado durante el proceso de explicación de la estructura tridimensional y helicoidal del ADN. En cuanto al conjunto de hipótesis auxiliares, conforme se fue desarrollando la investigación, presentó variaciones y cambios que mostraron, tanto confrontaciones y persistencias del cinturón protector; como progresiones y regresiones dependiendo ellos de la confrontación con los programas rivales de la época.

La explicación de la estructura tridimensional química del ADN se desarrolló bajo un método hipotético-deductivo. El progreso científico ocurrió mediante el cambio de programas de investigación en competencia que resultaron regresivos (Lakatos, 1983), como los postulados por L. Pauling (Pauling, 1953) o S. Furberg (Furberg, 1952).

Los postulados formulados para el modelo de la estructura química del ADN propuestos por J.Watson y F.Crick son básicos y de interés biológico considerable. La doble hélice, la externalidad de los grupos fosfato, las interacciones entre purinas y pirimidinas; pertenecieron al cinturón protector del programa. $\mathrm{Y}$ en la actualidad, se asumen como parte del núcleo firme de los programas de investigación que se relacionan con el desarrollo del dogma central de la biología molecular; el cual implica la transferencia de la información genética del ADN a las proteínas.

El proceso que condujo a la explicación del modelo de la estructura química del ADN se desarrollo mediante un programa de investigación que muestra que la ciencia no avanza obedeciendo a observaciones ateóricas, teorías aisladas, pruebas de ensayo y error o métodos basados únicamente en la experimentación. Por el contrario, requiere del apoyo interdisciplinario y en comunidad.

Es esta la lectura histórico-epistemológica que la responsable de este artículo ha querido destacar y someter a consideración de la comunidad de especialistas.

\section{BIBLIOGRAFÍA}

ASTBURY, W.T. 1947., Symp.Soc.Exp.Biol. 1, Nucleic Acid, 66.

CHARGAFF, L. 1952. Para la referencia ver Zamenhof, S., Brawerman, G. y Chargaff, E., Biochem. et. Biophys. Acta, 9, 402.

FURBERG, S. 1952. Acta Chem.Scand.Vol. 6, 634.

HOAGLAND, M.1993. Las Raíces de la Vida-Genes, Células y Evolución. Biblioteca Científica Salvat,1 - 167.

LAKATOS, I.1983. La Metodología del os Programas de Investigación Científica. ed. Alianza, Madrid.

PAULING, L. y COREY, R.B. 1953.Nature, 171, 346.

WATSON, J. \& CRICK, F. 1953. A structure for Deoxyribose Nucleic Acid. En: Rev. Nature, Vol.171. p.737. 
WATSON, J. 1987. La Doble Hélice. Biblioteca Científica Salvat. 1 - 147. 